\title{
Pengaruh Sistem Pengingat Melalui Pengiriman Pesan Singkat (Text- Messaging Reminder System) untuk Meningkatkan Kepatuhan Pasien dalam Pengobatan Tuberkulosis: Tinjauan Kasus Berbasis Bukti
}

\section{Effect of Reminder System through Text-Messaging for Increasing the Patient Adherence in Tuberculosis Medication: An Evidence-Based Case Report}

\author{
Skolastika M. Benedicta ${ }^{1}$, Pradana Soewondo ${ }^{2}$, Dhanasari V. Sanyoto ${ }^{3}$ \\ 1) Program Studi Pendidikan Dokter Fakultas Kedokteran Universitas Indonesia, Jakarta, Indonesia \\ 2) Divisi Metabolik Endokrin Departemen Ilmu Penyakit Dalam Fakultas Kedokteran Universitas Indonesia-Rumah \\ Sakit Umum Pusat Nasional Cipto Mangunkusumo, Jakarta, Indonesia \\ 3) Divisi Kedokteran Keluarga, Departemen Ilmu Kedokteran Komunitas Fakultas Kedokteran Universitas Indonesia- \\ Rumah Sakit Umum Pusat Nasional Cipto Mangunkusumo, Jakarta, Indonesia \\ Korespondensi: mitzysu@gmail.com
}

Submitted: 11 Juni 2019, Revised: 22 Agustus 2019, Accepted: 27 Agustus 2019

https://doi.org/10.22435/jpppk.v3i2.2331

\begin{abstract}
Abstrak
Indonesia merupakan negara kedua di dunia dengan insidensi Tuberkulosis (TB) terbanyak setelah India, sehingga Indonesia termasuk high-burden country dalam penyakit TB. Angka keberhasilan pengobatan TB di Indonesia baru mencapai 84\% pada tahun 2016 sehingga perlu ditingkatkan. Inovasi yang banyak dikembangkan untuk meningkatkan kepatuhan pasien dalam pengobatan TB adalah metode pengingat dengan menggunakan media elektronik, salah satunya melalui SMS mengingat pengguna aktif telepon genggam di Indonesia cukup banyak, yaitu mencapai 70,2 juta untuk smartphone pada tahun 2017 dan terus meningkat. Tujuannya untuk mengetahui pengaruh sistem pengingat melalui pesan singkat (text-messaging reminder system) dalam kepatuhan pasien terhadap pengobatan TB. Pencarian literatur dilakukan pada beberapa pangkalan data jurnal ilmiah kedokteran besar seperti Pubmed, Cochrane, EBSCOhost, dan Science Direct. Artikel disaring sesuai desain yang dibutuhkan untuk tinjauan intervensi, kriteria inklusi, dan kriteria eksklusi. Telaah kritis menggunakan metode intervensi sesuai Oxford Center for Evidence Based Medicine 2011. Telaah kritis dilakukan pada dua artikel terpilih dengan metode RCT dan telaah sistematis. Pada studi RCT terhadap 2207 pasien di Pakistan, diperoleh penggunaan sistem pengingat SMS tidak berpengaruh terhadap kepatuhan pengobatan TB. Pada telaah sistematis yang meninjau empat artikel, diperoleh kesimpulan bahwa sistem SMS mampu meningkatkan kepatuhan pengobatan TB. Namun, signifikansinya masih diragukan karena studi yang diinklusi merupakan studi dengan tingkatan bukti rendah berdasarkan kategori GRADE. Pengaruh metode pengingat berupa SMS terhadap kepatuhan pengobatan TB masih inkonklusif. Diperlukan penelitian lebih lanjut dengan populasi besar serta desain penelitian yang sesuai (RCT).
\end{abstract}

Kata kunci: Tuberkulosis, SMS, Sistem Pengingat, Kepatuhan, Pengobatan

\section{Abstract}

Indonesia ranked second in the world for its Tuberculosis (TB) incidence. Therefore, Indonesia is included in the list of high burden countries for TB. TB treatment success rate in Indonesia for 2016 is $84 \%$, but this number still needs to be increased. Many innovations using electronic devices such as handphones are developed to increase patient's adherence to TB treatment. One of the easiest applicable methods is through SMS. Indonesia is also a developing country with developing technology usage, with 70.2 million active smartphone users in 2017. To determine whether a text messaging reminder system can increase adherence in patients 
with Tuberculosis treatment. Literature searching was conducted in large medical journal databases such as Pubmed, Cochrane, EBSCOhost, and Science Direct. The articles are selected by considering the study designs that correlate with the intervention appraisal method, inclusions, and exclusions criteria. Intervention type appraisal was conducted using the guideline of the Oxford Center for Evidence-Based Medicine 2011. Appraisals were made for two chosen articles: one with the RCT method, and the other with a systematic review method. RCT study conducted in Pakistan showed that text messaging reminder system does not affect adherence in patients with TB treatment. The other study that reviews four articles concludes that a text messaging reminder system may increase adherence in TB patients undergoing treatment. But, the significance is still doubted as the studies included in this review are of low evidence level based on the GRADE category. The impact of the text messaging reminder system in increasing treatment adherence of TB patients is still inconclusive. Further research with a large population, better design and methodology are still needed.

\section{Keywords: Tuberculosis, SMS, Text Messaging, Reminder System, Adherence, Treatment}

\section{Pendahuluan}

Tuberkulosis (TB) masih merupakan penyakit yang menjadi masalah utama kesehatan di dunia, karena mortalitasnya adalah salah satu yang tertinggi, terutama pada negara berkembang seperti Indonesia. ${ }^{1}$ Indonesia sendiri merupakan negara kedua dengan insidensi TB terbanyak di dunia setelah India, sehingga termasuk high burden country akibat tingginya insidensi, prevalensi, serta mortalitas akibat penyakit TB. Prevalensi TB di Indonesia adalah 1,6 juta kasus pada tahun 2014, dengan insidensi sebanyak 1 juta kasus per tahunnya. $^{2}$

Salah satu program yang digagas WHO dan diadaptasi pemerintah dalam pemberantasan TB adalah strategi DOTS (directly observed treatment in short course). ${ }^{3}$ Pada tahun 2016, angka keberhasilan pengobatan TB di Indonesia mencapai 84\%, dengan angka keberhasilan DKI Jakarta baru mencapai $72 \% .{ }^{4}$ Angka ini masih menunjukkan diskrepansi di mana rata-rata negara di Asia Tenggara memiliki angka keberhasilan pengobatan TB yang sudah mencapai $85 \%$ atau lebih. Pengobatan TB yang sukses sangat bergantung pada efektivitas pengobatan yang membutuhkan kepatuhan selama seluruh jangka waktu pengobatan. Kepatuhan yang rendah pada pasien TB dapat menyebabkan berbagai dampak negatif seperti peningkatan transmisi, perpanjangan infeksi, resistensi, dan peningkatan biaya. ${ }^{4}$

Oleh karena itu, muncul gagasan strategi selain DOTS yang sedang dikembangkan untuk meningkatkan kepatuhan pasien dalam pengobatan TB. Salah satunya adalah melalui sistem pengingat menggunakan pesan singkat. Sistem ini bisa menjadi suatu terobosan mengingat pengguna aktif telepon genggam, khususnya smartphone mencapai 70,2 juta pengguna di Indonesia pada tahun 2015 dan jumlah ini diprediksi akan terus meningkat. ${ }^{5}$

Saat ini, belum ada penelitian terhadap sistem tersebut yang diadaptasi untuk kondisi Indonesia. Oleh karena itu, penelitian ini dibuat untuk mencari dan mengklarifikasi efektivitas strategi sistem pengingat melalui pesan singkat dalam meningkatkan kepatuhan pasien dalam pengobatan TB melalui bukti ilmiah agar dapat diimplimentasikan dalam praktik sehari-hari.

Sebagai contoh kasus, pasien laki-laki usia 34 tahun datang ke IGD dengan keluhan batuk darah hebat sejak 1 jam sebelum masuk rumah sakit. Selama 6 bulan terakhir pasien juga mengeluhkan batuk-batuk, menggigil, keringat malam hari, serta penurunan berat badan sebanyak $7 \mathrm{~kg}$. Pasien pernah terdiagnosis dengan TB paru 3 tahun lalu namun hanya meminum obat selama 3 bulan karena tidak ada orang yang mengingatkan dirinya untuk berobat. Pasien bertanya apakah ada metode lain yang dapat meningkatkan kepatuhannya dalam berobat.

Berangkat dari latar belakang dan kasus tersebut, dapat dibuat suatu pertanyaan klinis, yaitu: apakah sistem pengingat melalui pengiriman pesan dapat meningkatkan kepatuhan pasien dalam pengobatan TB ?

\section{Metode}

Pencarian literatur dilakukan pada tanggal 22 Februari 2018 di beberapa database besar seperti Pubmed, EBSCOHost, Science Direct, dan Cochrane. Kata kunci yang dipakai adalah "Reminder system", 
"Text messaging”, "Tuberculosis”, “Adherence”, "Treatment completion", "Treatment success" serta berbagai sinonim terkait. Pencarian artikel dibatasi dalam rentang sepuluh tahun terakhir.

Kriteria inklusi untuk seleksi artikel pada studi ini adalah jurnal yang dapat diakses dalam bahasa Inggris, dapat terakses naskah lengkap, serta studi dalam bentuk meta analisis, review, ataupun RCT. Selain itu, studi yang menjadi inklusi adalah studi pada populasi pasien TB primer yang baru pertama kali terdiagnosis dan memiliki keluaran berupa objektif untuk kepatuhan pengobatan TB. Kriteria eksklusi berupa studi dengan metode reminder selain SMS, seperti surat, voice message, alarm, ataupun kombinasi SMS dengan reminder lain serta studi pada populasi TB lain seperti koinfeksi pada HIV, TB MDR ataupun TB XDR.

Berdasarkan kata kunci yang digunakan, didapatkan 44 artikel dari Pubmed, 3 artikel dari Cochrane, 32 artikel dari Science Direct, dan 35 artikel EbscoHost. Dari hasil penyaringan pertama berdasarkan judul dan relevansinya terhadap pertanyaan klinis studi ini, diperoleh 6 artikel dengan jenis studi dan topik yang sesuai, sudah dipisahkan dengan duplikasinya. Enam artikel yang telah tersaring kemudian dibaca secara lengkap, dan diseleksi berdasarkan populasi dan parameter keluaran objektif sesuai kriteria inklusi. Dari hasil seleksi diperoleh dua artikel terpilih. Proses seleksi dapat dilihat pada Gambar 1.

Kedua artikel terpilih ini akan ditelaah kritis dari aspek validasi, kepentingan, dan

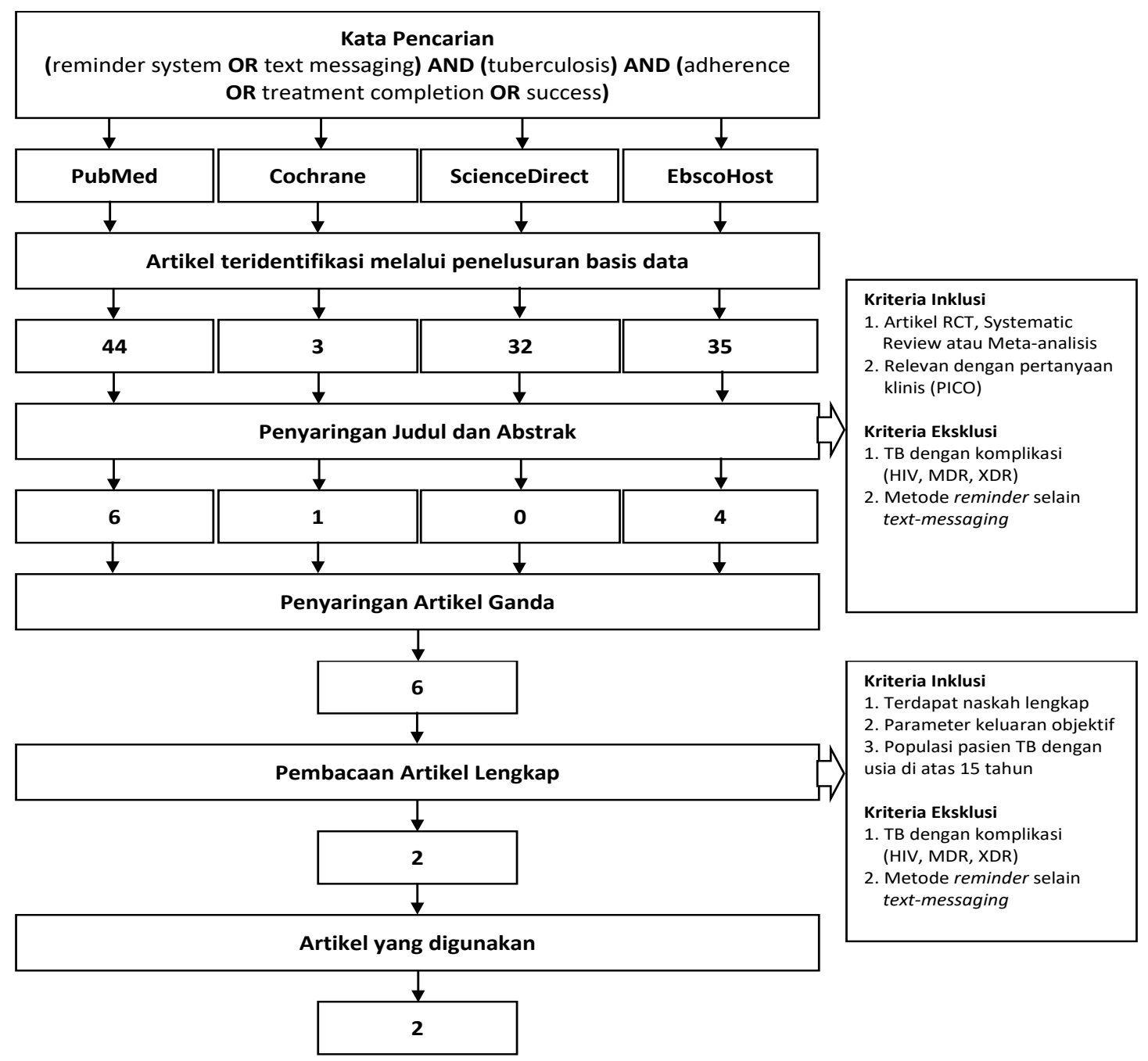

Gambar 1. Alur strategi pencarian dan seleksi artikel 
kemamputerapan berdasarkan format tinjauan kasus berbasis bukti jenis intervensi menurut Oxford Centre for Evidence-Based Medicine 2011.

\section{Hasil}

Diperoleh dua artikel yang diinklusikan pada studi ini, satu studi RCT dan satu merupakan systematic review. Pada pangkalan data besar, studi yang melibatkan penggunaan SMS sebagai sistem pengingat berobat pasien TB dan menggunakan parameter keluaran objektif WHO dalam pengobatan TB masih sangat terbatas. Hal ini tentu membuka peluang besar untuk penelitian lebih lanjut dalam bidang terkait.

Ada pun dalam hasil dan telaah yang akan dibahas dalam studi ini, kepatuhan yang dimaksud adalah kepatuhan terhadap pengobatan TB secara keseluruhan: dari perilaku kesehatan sesuai saran tenaga medis, pelaksanaan meminum obat antituberkulosis (OAT) hingga menghadiri pertemuan dengan dokter/tenaga kesehatan lain sesuai dengan jadwal. Kepatuhan ini diukur melalui keluaran parameter objektif sesuai WHO, yaitu (treatment success rate, completion rate, dan cure rate).

Mohammed et al (2016) melakukan studi berdesain RCT pada 2207 pasien yang baru terdiagnosis dengan TB dengan sistem Zindagi. Sistem ini mengingatkan pasien untuk meminum obat sesuai jadwal dan mengingatkan pasien untuk merespon ke sistem ketika sudah meminum obat. Apabila pasien tidak responsif selama satu minggu, maka tim akan menelpon atau mendatangi kediaman pasien terkait. Selain itu, sistem ini juga mengirimkan motivasi berobat harian pada pasien. Sekitar $85 \%$ populasi pasien dapat mengoperasikan sistem ini (dibuktikan dengan respon setidaknya sekali). Pada studi ini ditemukan bahwa sistem pengingat melalui pengiriman SMS tidak memiliki dampak signifikan pada pengobatan pasien dengan TB yang baru terdiagnosis. Dilakukan pula uji sputum dengan hasil yang tidak signifikan antara kedua kelompok. ${ }^{6}$

Dari aspek validitas, studi ini memiliki metode yang cukup baik dengan analisis intention to treat, pengelompokan dengan randomisasi dan metode blinding juga dirincikan dengan baik. Seluruh kelompok juga diberi perlakuan sesuai dengan standar nasional. Pada studi ini, pasien yang diinklusi merupakan pasien yang baru terdiagnosis TB dengan bakteriologis positif, di atas usia 15 tahun, dan memiliki akses terhadap telepon genggam. Adapun persebaran karakteristik demografi di kedua kelompok seperti jenis kelamin, usia, pendidikan, dan lama pengobatan bersifat homogen. Namun, tidak ada identifikasi komorbiditas pada kelompok studi seperti infeksi DM atau HIV (Tabel 1 dan Tabel 3).

Dari aspek importance, pada studi ini ditemukan bahwa sistem pengingat dengan SMS tidak memiliki dampak signifikan pada pasien dengan Tuberkulosis yang baru terdiagnosis. Hal ini dibuktikan dengan ARR 0,4\% (Tabel 1) yang berarti kepatuhan pengobatan TB pada pasien dengan intervensi dan tanpa intervensi sama saja. Numbers needed to treat (NNT) pada penelitian ini juga sangat besar, kita perlu mengobati 250 pasien untuk meningkatkan kepatuhan pengobatan satu pasien dengan TB melalui SMS. ${ }^{6}$

Telaah kritis yang dilakukan oleh Nglazi et $\mathrm{al}^{7}$ menginklusikan empat studi dengan total 565 partisipan. Tiga studi merupakan studi observasional

Tabel 1. Telaah kritis pada Studi RCT yang diinklusi

\begin{tabular}{|c|c|c|c|c|c|c|c|c|c|c|c|c|c|c|c|c|}
\hline \multirow[b]{2}{*}{ Artikel } & \multirow[b]{2}{*}{$\begin{array}{l}\text { Study } \\
\text { design }\end{array}$} & \multicolumn{5}{|c|}{ Validity } & \multicolumn{7}{|c|}{ Importance } & \multicolumn{3}{|c|}{ Applicability } \\
\hline & & 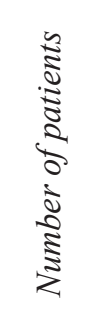 & 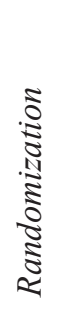 & 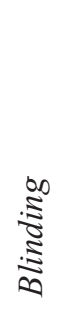 & 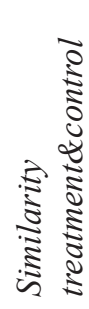 & 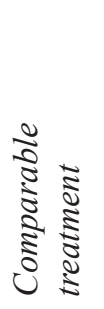 & 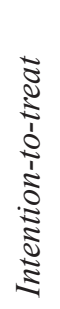 & 昰 & 疍 & 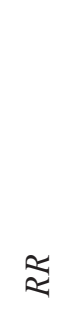 & $\stackrel{\nwarrow}{\sharp}$ & $\sum_{z}^{k}$ & 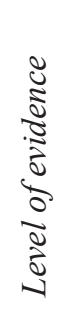 & 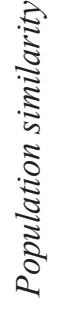 & 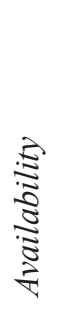 & 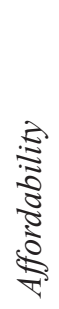 \\
\hline $\begin{array}{l}\text { Mohammed } \\
\text { et al, } 2016\end{array}$ & $\mathrm{RCT}$ & 2207 & + & + & + & + & + & $83 \%$ & $82,6 \%$ & 1,0 & $0,4 \%$ & 250 & $1 b$ & + & + & + \\
\hline
\end{tabular}


Tabel 2. Telaah kritis pada Studi Telaah Sistematis yang diinklusi

\begin{tabular}{|c|c|c|c|c|c|c|c|c|c|c|c|c|c|c|c|}
\hline \multirow[b]{2}{*}{ Article } & \multirow[b]{2}{*}{$\begin{array}{l}\text { Study } \\
\text { Design }\end{array}$} & \multicolumn{4}{|c|}{ Validity } & \multicolumn{4}{|c|}{ Applicability } & & \multicolumn{5}{|c|}{ Importance } \\
\hline & & $e_{2}^{0}$ & 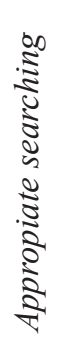 & 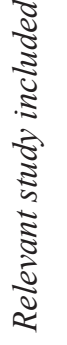 & 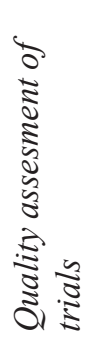 & 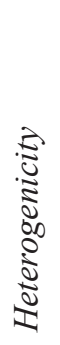 & 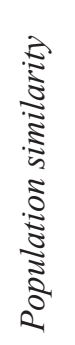 & 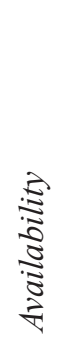 & 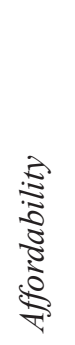 & $\begin{array}{l}\text { Study } \\
\text { Included }\end{array}$ & 通 & 选 & 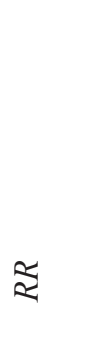 & $\sum_{z}$ & 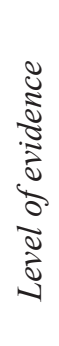 \\
\hline \multirow{3}{*}{$\begin{array}{l}\text { Nglazi et } \\
\text { al, } 2013\end{array}$} & $\begin{array}{l}\text { Systema- } \\
\text { tic }\end{array}$ & & & & & & & & & $\begin{array}{l}\text { Bridges } \\
\text {.org }\end{array}$ & $72,9 \%$ & $69,4 \%$ & 1,05 & 28 & $3 b$ \\
\hline & Review & + & + & + & + & + & + & + & + & Broom-head & $75 \%$ & $32,3 \%$ & 2,32 & 3 & $2 b$ \\
\hline & $\begin{array}{c}\text { Level of } \\
\text { evidence: } \\
3 \mathrm{a}\end{array}$ & & & & & & & & & $\begin{array}{l}\text { Iribarren } \\
\text { Owiti, et al }\end{array}$ & $\begin{array}{l}77 \% \\
67,2 \%\end{array}$ & $\begin{array}{l}53 \% \\
43,2 \%\end{array}$ & $\begin{array}{l}1,49 \\
1,56\end{array}$ & $\begin{array}{l}5 \\
5\end{array}$ & $\begin{array}{l}2 b \\
3 b\end{array}$ \\
\hline
\end{tabular}

dan hanya satu yang memiliki desain RCT karena keterbatasan ketersediaan literatur. Studi ini telah menginklusikan beberapa studi dengan metode pencarian yang cukup baik dari pangkalan data besar dan sesuai dengan pertanyaan klinis sehingga dari aspek validitas, studi ini dinyatakan valid (Tabel 2). Namun, heterogenitas pada keluaran klinis dan metodologi dari studi yang ada menyebabkan tidak dapat dilakukan analisis meta pada data tersebut.

Jika dilihat dari aspek importance, angka NNT pada masing-masing penelitian yang ditelaah oleh Nglazi et al ${ }^{7}$ memiliki range dari 3-28 (Tabel 2). Angka tersebut menunjukkan bahwa intervensi dalam bentuk SMS cukup berpengaruh dalam meningkatkan kepatuhan dalam pengobatan TB. Secara keseluruhan, studi menunjukkan bahwa pasien yang menerima pengingat dalam bentuk SMS memiliki kepatuhan pengobatan TB yang lebih baik dibandingkan grup kontrol. Meskipun begitu, sedikitnya jumlah sampel penelitian serta rendahnya level of evidence studi yang diinklusikan pada review ini menyulitkan pengambilan keputusan. Lebih lanjut, masing-masing karakteristik studi yang diinklusikan dalam telaah kritis Nglazi et al dapat dilihat pada Tabel 3 . $^{7}$

Lebih lanjut, telaah dari aspek kemamputerapan/applicability menunjukkan bahwa meskipun kedua riset menunjukkan hasil yang berbeda, tetapi penerapan sistem SMS sebagai pengingat pengobatan TB masih mampulaksana karena membutuhkan teknologi yang relatif sederhana dan dapat dilakukan dengan sumber daya terbatas. Adapun target yang dapat terjangkau dengan metode ini juga cukup luas, mengingat lebih dari 30\% penduduk Indonesia menggunakan smartphone, dengan trend yang terus meningkat dari waktu ke waktu. ${ }^{5}$

\section{Diskusi}

Studi Mohammed et al menunjukkan bahwa SMS yang diintensikan untuk meningkatkan ingatan pasien dalam berobat tidak mengatasi faktor yang mendasari pasien putus berobat. ${ }^{6}$ Laju respons yang selalu menurun dan memiliki nilai mean rendah (29\%) menunjukkan bahwa pasien lelah dengan pengingat harian. Penelitian lain pada pasien dengan HIV menunjukkan kepatuhan meningkat hanya pada kelompok yang menerima pengingat mingguan. ${ }^{8}$

Selain itu, pada penelitian ini, populasi tidak dikhususkan pada pasien tanpa pengawas minum obat (PMO). Hasil yang lebih mencerminkan signifikansi intervensi SMS mungkin dapat dilihat apabila populasi dikhususkan untuk pasien yang harus meminum obat sendiri. Mengingat Indonesia 
Tabel 3. Karakteristik penelitian yang diinklusikan pada Review oleh Nglazi et al7 dan RCT oleh Mohammed et al ${ }^{6}$

\begin{tabular}{|c|c|c|c|c|c|}
\hline Studi & Metode & Populasi & Intervensi & Keluaran & Keterangan \\
\hline $\begin{array}{l}\text { Bridges. } \\
\text { Org } \\
(2005)\end{array}$ & $\begin{array}{l}\text { Evaluasi } \\
\text { data } \\
\text { kuantitatif } \\
\text { dan } \\
\text { kualitatif }\end{array}$ & $\begin{array}{l}\text { Pasien } \\
\text { dengan } \\
\text { TB pada } \\
\text { Direktorat } \\
\text { Cape Town }\end{array}$ & $\begin{array}{l}\text { Pengingat SMS } \\
\text { dikirim setiap } \\
\text { hari kepada } \\
\text { pasien tanpa } \\
\text { pengawas } \\
\text { minum obat }\end{array}$ & $\begin{array}{l}\text { Treatment } \\
\text { success rate }\end{array}$ & $\begin{array}{l}\text { Kelebihan: } \\
\text { - Jumlah sampel banyak }(\mathrm{n}=221) \\
\text { - } \quad \text { Membandingkan intervensi SMS } \\
\text { dengan DOTS } \\
\text { Kekurangan } \\
\text { - } \quad \text { Metode blinding tidak disebutkan } \\
\text { - } \quad \text { Tidak ada spesifikasi jumlah dan } \\
\quad \text { perlakuan grup kontrol }\end{array}$ \\
\hline $\begin{array}{l}\text { Broom- } \\
\text { head } \\
(2012)\end{array}$ & $\begin{array}{l}\text { Kohort } \\
\text { retrospektif }\end{array}$ & $\begin{array}{l}\text { Pasien TB } \\
\text { terdiagnosis } \\
\text { pertama kali } \\
\text { dengan } 6 \\
\text { bulan masa } \\
\text { pengobatan }\end{array}$ & $\begin{array}{l}\text { Sistem MAS - } \\
\text { suatu alat yang } \\
\text { ditempelkan } \\
\text { pada botol } \\
\text { pil dan } \\
\text { mengirimkan } \\
\text { SMS sebagai } \\
\text { pengingat }\end{array}$ & TB cure rate & $\begin{array}{l}\text { Kelebihan } \\
\text { - } \quad \text { Membandingkan intervensi } \\
\text { menggunakan SMS dengan kontrol } \\
\text { grup hanya menerima DOTS saja } \\
\text { Kekurangan } \\
\text { - Jumlah sampel sedikit }(\mathrm{n}=24) \\
\text { - Tidak dijelaskan metode blinding }\end{array}$ \\
\hline $\begin{array}{l}\text { Iri- } \\
\text { Barren } \\
(2012)\end{array}$ & $\begin{array}{l}\text { Studi pilot } \\
\text { dengan } \\
\text { paralell } \\
\text { design } \\
\text { RCT }\end{array}$ & $\begin{array}{l}37 \text { pasien } \\
\text { yang baru } \\
\text { terdiagnosis } \\
\text { TB pertama } \\
\text { kali (18 pada } \\
\text { kelompok } \\
\text { intervensi } \\
\text { dan } 19 \text { pada } \\
\text { kelompok } \\
\text { kontrol) }\end{array}$ & $\begin{array}{l}\text { Pelayanan } \\
\text { standar ditambah } \\
\text { SMS untuk } \\
\text { instruksi } \\
\text { pengingat } \\
\text { minum obat dan } \\
\text { konsultasi }\end{array}$ & $\begin{array}{l}\text { Self- } \\
\text { report via } \\
\text { medication } \\
\text { calendar }\end{array}$ & $\begin{array}{l}\text { Kelebihan } \\
\text { - Metode RCT } \\
\text { - Analisis intention-to-treat } \\
\text { Kekurangan } \\
\text { - Jumlah sampel sedikit }(\mathrm{n}=37) \\
\text { - Menghitung kepatuhan hanya pada } \\
\text { masa pengobatan intensif (2 bulan) } \\
\text { Tidak ada spesifikasi metode } \\
\text { dan penyembunyian randomisasi } \\
\text { ataupun blinding }\end{array}$ \\
\hline $\begin{array}{l}\text { Owiti } \\
(2012)\end{array}$ & $\begin{array}{l}\text { Feasibility } \\
\text { pilot study }\end{array}$ & $\begin{array}{l}\text { Pasien TB } \\
\text { dengan akses } \\
\text { telepon } \\
\text { genggam }\end{array}$ & $\begin{array}{l}\text { SMS pengingat } \\
\text { clinical } \\
\text { appointment, } \\
\text { satu hari } \\
\text { sebelum janji } \\
\text { kontrol di klinik }\end{array}$ & $\begin{array}{l}\text { Kehadiran di } \\
\text { klinik sesuai } \\
\text { jadwal } \\
\text { perjanjian }\end{array}$ & $\begin{array}{l}\text { Kelebihan: } \\
\text { - Jumlah sampel banyak }(\mathrm{n}=187) \\
\text { - } \quad \text { Tidak ada data hilang } \\
\text { Kekurangan } \\
\text { - } \quad \text { Tidak ada spesifikasi blinding dan } \\
\text { randomisasi } \\
\text { - Tidak menggunakan intention to } \\
\text { treat analysis }\end{array}$ \\
\hline $\begin{array}{l}\text { Moham- } \\
\text { med } \\
(2016)\end{array}$ & $\mathrm{RCT}$ & $\begin{array}{l}\text { Pasien } \\
\text { terdiagnosis } \\
\text { TB pertama } \\
\text { kali, di atas } \\
\text { usia } 15 \text { tahun, } \\
\text { memiliki } \\
\text { akses telepon } \\
\text { genggam }\end{array}$ & $\begin{array}{l}\text { Zindagi } \\
\text { SMS - sistem } \\
\text { SMS untuk } \\
\text { mengingatkan } \\
\text { kapan minum } \\
\text { obat dan } \\
\text { motivasi harian } \\
\text { untuk minum } \\
\text { obat }\end{array}$ & $\begin{array}{l}\text { TB success } \\
\text { rate, } \\
\text { completion } \\
\text { rate, cure } \\
\text { rate }\end{array}$ & $\begin{array}{l}\text { Kelebihan } \\
\text { - } \quad \text { RCT dengan jumlah sampel banyak } \\
\text { - } \quad \text { Rand207) } \\
\text { dideskripsikan } \\
\text { - } \quad \text { Analisis intention to treat } \\
\text { Kekurangan } \\
\text { - } \quad \text { Komorbiditas dan kategori TB } \\
\text { tidak diidentifikasi } \\
\text { - } \quad \text { Grup kontrol tidak dijelaskan } \\
\text { Ada 9\% data hilang }\end{array}$ \\
\hline
\end{tabular}

* Cure rate: persentase pasien yang terdiagnosis TB dengan sputum positif dan berubah menjadi negatif setelah menyelesaikan jangka waktu pengobatan secara lengkap

* Completion rate: pasien terdiagnosis TB yang telah menjalani pengobatan secara lengkap hingga akhir tanpa konfirmasi bakteriologis untuk menentukan kesembuhan

* Treatment success rate: cure rate ditambah dengan completion rat 
yang mengaplikasikan sistem Directly-observed Therapy (DOT), penelitian ini juga masih mungkin menghasilkan signifikansi yang berbeda apabila ditujukan kepada pengawas obat.

Hal lain yang dapat dipertimbangkan adalah laju keberhasilan pengobatan di Pakistan pada tahun 2012 yang sudah mencapai $91 \% .{ }^{9}$ Intervensi SMS masih mungkin menghasilkan signifikansi berbeda apabila diterapkan di Indonesia yang memiliki laju keberhasilan pengobatan TB lebih rendah, yaitu $84 \%$ di tahun $2016 .{ }^{4}$

Menilik studi Nglazi et al, diperoleh hasil yang berbeda, yaitu peningkatan kepatuhan pengobatan pasien TB dengan metode pengingat berupa pengiriman SMS dibandingkan grup kontrol. Namun, sedikitnya jumlah sampel penelitian serta rendahnya level of evidence studi yang diinklusikan pada review ini menyulitkan pengambilan kesimpulan. $^{7}$

Meskipun begitu, potensi SMS sebagai media pengantar informasi ke pasien tetap tidak dapat diabaikan. Meningkatnya akses terhadap telepon genggam dan penggunaan SMS, bahkan internet bisa menjadi sarana untuk mengantarkan pesan kesehatan singkat kepada banyak orang tanpa terbatas waktu dan ruang. Selain itu, metode ini juga dapat memberikan umpan balik dan dukungan secepatnya ketika pasien membutuhkan.

Berbagai macam riset sebelumnya telah menunjukkan efektivitas intervensi berupa SMS untuk meningkatkan kesehatan pasien seperti kepatuhan terhadap kontrol dan penanganan berbagai penyakit kronik seperti hipertensi dan diabetes, penyakit jantung koroner, terapi antiretroviral pada pasien dengan AIDS, hingga program berhenti merokok. ${ }^{8,10-12}$ Namun, efektivitas sistem ini dalam pengobatan TB masih tidak dapat disimpulkan. Butuh penelitian lebih lanjut dengan populasi besar dan desain penelitian yang lebih baik untuk memperoleh hasil yang lebih valid.

TB merupakan penyakit kronis dengan perjalanan penyakit yang tidak sebentar. Namun, dengan tatalaksana dan strategi preventif yang sesuai, bukan tidak mungkin penyakit ini dieradikasi. Peran pelayanan kesehatan primer sebagai ujung tanduk pelayanan kesehatan di Indonesia tentu tidak dapat diabaikan dalam menanggulangi TB. DOTS yang diimplementasikan di Indonesia juga paling terutama melibatkan komponen pelayanan kesehatan primer. Oleh karena itu, peran model baru yang dapat meningkatkan efektivitas program pelayanan kesehatan primer, contohnya seperti implementasi chronic care model $(\mathrm{CCM})^{13}$ tentu bisa menjadi sangat bermanfaat. Hal ini telah dibuktikan dalam berbagai penelitian, meskipun belum ada implementasinya di Indonesia. ${ }^{14-16}$

Inovasi baru seperti metode pengingat dalam bentuk SMS masih menjadi mampu laksana dalam setting pelayanan primer. Selain dapat dilakukan dengan otomatisasi sehingga tidak memerlukan banyak sumber daya, sistem ini dapat mencakup banyak pasien sekaligus, sehingga bisa mengurangi beban kerja dan biaya. Pada perkembangan teknologi sekarang ini, penggunaan alat elektronik dalam meningkatkan kesehatan tentu memiliki tempat tersendiri.

Metode pengingat dalam bentuk teks elektronik dapat dimasukkan ke dalam CCM sebagai inovasi pada komponen dukungan manajemen individu. Sistem pengingat melalui pengiriman SMS dapat memfasilitasi peran sentral pasien dalam menjaga kesehatannya sendiri. Sistem ini juga mampu menguatkan strategi pada desain pengantaran sistem dari segi follow-up agar kita yakin betul, bahwa dukungan manajemen individu dan pelayanan klinis efektif yang diberikan benar dirasakan pada pasien. ${ }^{13}$

Suatu penelitian di Brazil menyatakan bahwa program pelayanan kesehatan primer terkait TB dalam bidang dukungan manajemen individu dan desain pengantaran pelayanan masih dalam tahap suboptimal, terutama dalam kontinuitas pelayanan kesehatan bagi pasien dengan TB. ${ }^{17}$ Oleh karena itu, inovasi baru berupa pengingat via SMS diharapkan mampu memberdayakan pasien dalam manajemen diri sendiri dan memudahkan klinisi dalam followup agar didapatkan hasil yang maksimal.

Penelitian lebih lanjut pada populasi di Indonesia dibutuhkan untuk melihat efektivitas program sehingga dapat dinilai perannya dalam chronic care model di pelayanan kesehatan primer.

\section{Kesimpulan}

Berdasarkan telaah kritis yang telah dilakukan, penggunaan sistem pengingat dengan metode pengiriman SMS dapat meningkatkan 
kepatuhan pengobatan pada lebih banyak pasien dibandingkan tanpa intervensi. Namun, peningkatan kepatuhan pada pasien dengan intervensi tersebut masih belum terlihat signifikan. Rendahnya level of evidence dari data yang diperoleh, menyebabkan pengaruh metode SMS terhadap kepatuhan pasien terhadap pengobatan TB ini masih inkonklusif.

Metode pengingat dalam bentuk SMS masih mampu laksana untuk diterapkan pada populasi pasien TB di Indonesia. Namun, SMS tidak disarankan sebagai metode tunggal untuk meningkatkan kepatuhan pada pasien dalam pengobatan TB, kombinasi SMS dengan berbagai sarana lain seperti surat, telepon, atau kunjungan khusus dirasa mampu meningkatkan kepatuhan pasien dalam pengobatan TB dengan lebih signifikan.

\section{Saran}

Penelitian lebih lanjut dengan desain RCT, metodologi yang baik, dan intervensi sesuai masih perlu dilakukan untuk menjawab pertanyaan akan efektivitas metode pengingat dalam bentuk pesan singkat dalam pengobatan TB. Terutama, penelitian pada populasi di Indonesia sehingga kita dapat menentukan apakah metode ini dapat diterapkan, sebagai salah satu upaya chronic care model di pelayanan kesehatan primer.

\section{Daftar Pustaka}

1. K Dheda, Barry CE, Maartens G. Tuberculosis [Summary]. Lancet [Internet]. 2015 [diakses pada 24 Februari 2018]; vol 387: 1211-26. Tersedia pada: DOI:https://doi.org/10.1016/ S0140-6736(15)00151-8

2. World Health Organization. Global tuberculosis report 2016. Geneva:WHO Library Cataloguingin-Publication Data [Internet]. 2016 [diakses pada 24 Februari 2018]. Tersedia pada: https:// apps.who.int/medicinedocs/documents/ s23098en/s23098en.pdf

3. Kementerian Kesehatan RI. Strategi Nasional pengendalian TB di Indonesia 2010-2014. Jakarta: Direktorat Jenderal Pengendalian Penyakit dan Penyehatan Lingkungan [Internet]; 2011 [diakses pada 24 Februari 2018]. Tersedia pada:https://www.who.int/docs/defaultsource/searo/indonesia/stranas-tb-2010-2014. pdf?sfvrsn=aa7e44a9_2
4. Kementerian Kesehatan. Tuberkulosis temukan obati sampai sembuh. Jakarta: Pusat Data dan Informasi Kementrian Kesehatan RI.; 2016 [diakses pada 24 Februari 2018]. 2016. Tersedia pada: https://pusdatin.kemkes.go.id/resources/ download/pusdatin/infodatin/InfodatinTB-2016.pdf

5. Statista. Number of smartphone users in Indonesia from 2011 to 2022 (in millions) [web page on the internet]. 2017 [diakses pada 24 Feb 2018]. Tersedia pada: https://www.statista. com/statistics/266729/smartphone-users-inindonesia/

6. Mohammed S, Glennerster R, Khan AJ. Impact of a daily SMS medication reminder system on tuberculosis treatment outcomes: A randomized controlled trial. PLoS One [Internet]. 1 Nov 2016 [diakses pada 24 Februari 2018];11(11). Tersedia pada: https://www.ncbi.nlm.nih.gov/ pmc/articles/PMC5089745/pdf/pone.0162944. pdf. DOI:10.1371/journal.pone.0162944

7. Nglazi MD, Bekker LG, Wood R, Hussey GD, Wiysonge CS. Mobile phone text messaging for promoting adherence to anti-tuberculosis treatment: a systematic review. BMC Infect Dis [Internet]. 2013 [diakses pada 24 Februari 2018];13(566). 1-16. Tersedia pada: https://www.ncbi.nlm.nih.gov/pmc/articles/ PMC4219402/pdf/1471-2334-13-566.pdf

8. Finitsis DJ, Pellowski JA, Johnson BT. Text message intervention designs to promote adherence to antiretroviral therapy (ART): A meta-analysis of randomized controlled trials. PLoS One [Internet]. 2014 [diakses pada 24 Februari 2018]; 9(2). Tersedia pada: https://www.ncbi.nlm.nih.gov/pmc/articles/ PMC3914915/pdf/pone.0088166.pdf

9. World Health Organization. Pakistan tuberculosis [web page on the internet]. 2018 [diakses pada 24 Feb 2018]. Tersedia pada: http://www.emro.who.int/pak/programmes/ stop-tuberculosis.html

10. de Jongh T, Gurol-Urganci I, Vodopivec-Jamsek V, Car J, Atun R. Mobile phone messaging for facilitating self-management of long-term illnesses (Review). Cochrane Database Syst Rev [Internet]. 2012 [diakses pada 24 Februari 2018]; issue 12. Tersedia pada: https://www. 
ncbi.nlm.nih.gov/pmc/articles/PMC6486189/ pdf/CD007459.pdf

11. Zhao YY, Dang FP, Zhai TT, Li HJ, Wang RJ, Ren JJ. The effect of text message reminders on medication adherence among patients with coronary heart disease: A systematic review and meta-analysis. Medicine. 2019 [diakses pada 24 Februari 2018];98(52). Pp. 1-7. Tersedia pada: https://www.ncbi.nlm.nih. gov/pmc/articles/PMC6946488/pdf/medi98-e18353.pdf. DOI: http://dx.doi.org/10.1097/ MD.0000000000018353

12. Whittaker R, McRobbie H, Bullen C, Rodgers $\mathrm{A}, \mathrm{Gu}$ Y. Mobile phone-based interventions for smoking cessation (Review). Cochrane Database Syst Rev [Internet]. 2016 [diakses pada 24 Februari 2018] ; issue 4. Tersedia pada: https://www.ncbi.nlm.nih.gov/pmc/articles/ PMC6485940/pdf/CD006611.pdf. DOI: DOI: 10.1002/14651858.CD006611.pub4.

13. Group Health Research Institute. Improving chronic illness care [web page on the Internet]. 2016 [diakses pada 24 Feb 2018]. Tersedia pada: http://www.improvingchroniccare.org/ index.php?p=1:_Models\&s $=363$

14. Lorig KR, Sobel DS, Stewart AL, Brown BW Jr, Bandura A, Ritter $\mathrm{P}$, et al. Evidence suggesting that a chronic disease self-management program can improve health status while reducing utilization and costs: A randomized trial [Abstrak]. Med Care [Internet]. 1999 [diakses pada 24 Februari 2018]; 37(1):5- 14. Tersedia pada: https://journals.lww.com/lwwmedicalcare/Abstract/1999/01000/Evidence Suggesting_That_a_Chronic_Disease.3.aspx.

15. Stellefson M, Dipnarine K, Stopka C. The chronic care model and diabetes management in US primary care settings: A systematic review. Prev Chronic Dis [Internet]. 2013 [diakses pada 24 Februari 2018];10:E26. Tersedia pada: https://www.ncbi.nlm.nih.gov/pmc/articles/ PMC3604796/pdf/PCD-10-E26.pdf.DOI: http://dx.doi.org/10.5888/pcd10.120180.

16. Coleman K, Austin BT, Brach C, Wagner EH. Evidence on the chronic care model in the new millenium. Health Aff (Millwood) [Internet]. 2 Nov 2016 [diakses pada 24 Februari 2018];28(1). Tersedia pada: https://www.ncbi.nlm.nih.gov/ pmc/articles/PMC5091929/pdf/nihms825200. pdf. DOI: 10.1377/hlthaff.28.1.75.

17. da Silva DM, de Farias HBG, Villa TCS, de Sá LD, Brunello MEF, Nogueira JA. Care production for tuberculosis cases: analysis according to the elements of the Chronic Care Model. Rev Esc Enferm USP [Internet]. 2016 [diakses pada 24 Februari 2018];50(2):237244. Tersedia pada: http://www.scielo.br/pdf/ reeusp/v50n2/0080-6234-reeusp-50-02-0239. pdf. DOI: http://dx.doi.org/10.1590/S0080623420160000200009 